\title{
Nanopartículas Sintetizadas por Bacterias Antárticas y sus Posibles Mecanismos de Síntesis
}

\author{
Nanoparticles Synthesized by Antarctic Bacteria and their Possible Mechanisms of Synthesis
}

\author{
Andrés Santos ${ }^{1,2}$; Claudia Troncoso ${ }^{1,2,3}$; Claudio Lamilla ${ }^{1,2}$; \\ Vicente Llanquinaoo $^{1,2}$; Mónica Pavez ${ }^{1,2}$ \& Leticia Barrientos ${ }^{1,2}$
}

SANTOS, A.; TRONCOSO, C.; LAMILLA, C.; LlANQUINAO, V.; PAVEZ, M. \& BARRIENTOS, L. Nanopartículas sintetizadas por bacterias antárticas y sus posibles mecanismos de síntesis. Int. J. Morphol., 35(1):26-33, 2017.

RESUMEN: En los últimos años microorganismos tales como hongos, levaduras y, en especial, las bacterias han sido utilizadas para realizar biosíntesis de nanopartículas. Existen varios tipos de bacterias descritas como productoras de nanopartículas, sin embargo, las bacterias psicrófilas y psicrotolerantes no han sido ampliamente estudiadas, aun cuando su utilización en la producción de nanopartículas podría entregar ventajas relacionadas con su estabilidad, el gasto energético de su producción, al mismo tiempo que son una alternativa amigable con el medio ambiente. Este artículo entrega una breve revisión de las bacterias antárticas psicrófilas y psicrotolerantes sintetizadoras de nanopartículas, los posibles mecanismos que se asocian a esta síntesis y perspectivas futuras relacionadas a la biosíntesis bacteriana de nanopartículas.

PALABRAS CLAVE: Nanopartículas; Biosíntesis; Bacterias antárticas.

\section{INTRODUCCIÓN}

La nanotecnología incluye la producción, manipulación y el uso de materiales de un tamaño igual o menor a 100 nanómetros (nm) llamados nanopartículas (Daniel \& Astruc, 2004; Kirthi et al., 2013). Las nanopartículas pueden tener diferentes tamaños y su morfología puede ser amorfa, cristalina, esférica o triangular. Los nanomateriales pueden incluir nanopartículas orgánicas o inorgánicas. Una característica esencial de las nanopartículas es que al tener tamaños tan pequeños modifican las propiedades físicas, químicas y biológicas de las partículas, y a la vez modifican las reglas de la mecánica cuántica, las cuales determinan el comportamiento de la materia y la luz a nivel atómico y sub atómico, ocasionando que tengan propiedades ópticas, eléctricas y magnéticas que difieren sustancialmente de partículas más grandes de un mismo elemento (Dowling et al., 2004), incluyendo partículas ultrafinas de metales, óxidos metálicos, no metales y cerámicas (Kirthi et al.). Es por eso que las nanopartículas tienen una diversidad de aplicaciones, las cuales dependen de su tamaño, forma y estabilidad (Salunke et al., 2016).

En medicina, las nanopartículas se han utilizado para el mejoramiento en el diagnóstico y tratamiento de enfer- medades, y también, en el marcaje de biomoléculas (Fadeel \& Garcia-Bennett, 2010). Uno de los principales usos en el área médica, se refieren a la utilización de las nanopartículas en la administración de fármacos, en los cuales éstas funcionan como transportadores, que han podido ser dirigidos, y tienen la ventaja de poder desplazarse sin mayor dificultad a través de la sangre y tejidos para llegar finalmente a la célula blanco. Además, se ha visto que debido a su pequeño tamaño, los transportadores de fármacos pueden atravesar la barrera hemato-encefálica, así como también las barreras epiteliales que, generalmente, impiden el suministro de fármacos en el sitio blanco deseado, y en consecuencia generan una acción inespecífica (Fadeel \& Garcia-Bennett). Por otra parte, las nanopartículas fluorescentes tienen también varios tipos de aplicaciones en áreas de la biomedicina, en donde se han usado en la detección del cáncer (PérezDonoso et al., 2012).

Otra importante área de aplicación de las nanopartículas está en la agricultura; en esta área se utilizan principalmente como nanopesticidas y nanoherbicidas. Varias industrias generan formulaciones que contienen

\footnotetext{
1 Laboratorio de Biología Molecular Aplicada, Centro de Excelencia en Medicina Traslacional. Avenida Alemania 0458, Temuco, 4810296.

2 Núcleo Científico y Tecnológico en Biorecursos (BIOREN), Universidad de La Frontera, Temuco - Chile.

${ }^{3}$ Universidad Autónoma de Chile, Temuco - Chile.
} 
nanopartículas de entre 100-250 nm, empleándose generalmente nanoemulsiones que contienen suspensiones uniformes de las nanopartículas de pesticidas o de herbicidas (Yakub \& Soboyejo, 2012).

En el área de las energías renovables, se han utilizado nanopartículas de CdTe en paneles solares, las cuales cumplen funciones de generación y conducción de electricidad (Monrás et al., 2012).

La síntesis de nanopartículas es claramente el proceso esencial para todo lo que se comentó anteriormente en torno a sus características y aplicaciones. Para lograr la síntesis de las nanopartículas existen diversos métodos; la síntesis más comúnmente realizada, es la síntesis química, la cual se lleva a cabo con la utilización de métodos como síntesis sol-gel, métodos de reducción química, tecnología aerosol, litografía, entre otros (Dowling et al.). Estos métodos permiten generar grandes cantidades de nanopartículas, sin embargo, los métodos de síntesis química son métodos que requieren de un gran gasto energético y, además, requieren, generalmente, del uso de químicos peligrosos y de reactivos altamente contaminantes en grandes cantidades (Bansal et al., 2014).

No obstante, existen variados tipos de microorganismos que pueden producir diferentes tipos de nanopartículas, cuya biosíntesis no requiere altas presiones ni altas temperaturas, lo que significa que no hay un gran gasto energético involucrado. Además, se ha demostrado que la biosíntesis de nanopartículas es viable económicamente y que son procesos escalables a nivel industrial (Kirthi et $a l$.). Actualmente, las bacterias son consideradas como potenciales biosintetizadores de varios tipos de nanopartículas, y dicha cualidad se asocia directamente a la capacidad de algunas especies de ser resistentes al estrés oxidativo. Un ejemplo de este tipo de bacterias son los microrganismos psicrófilos que están expuestos normalmente a este tipo de estrés oxidativo, debido a las condiciones hostiles de sus ecosistemas, lo cual le entregaría a la bacteria la maquinaria necesaria para la síntesis de nanopartículas (Klaus-Joerger et al., 2001 \& Lengke et al., 2007).

De esta forma entonces, la Antártica representaría una importante fuente de este tipo de microorganismos debido a la alta radiación y las bajas temperaturas que deben sobrellevar las bacterias que allí habitan, condiciones que inducen estrés oxidativo en las bacterias, potenciando esta cualidad necesaria para esta biosíntesis (Chattopadhyay et al., 2011 \& Gallardo et al., 2014). Algunos estudios han demostrado que las bajas temperaturas, pueden mejorar los procesos de síntesis y a la vez mejorar la estabilidad de las nanopartículas; además, se pueden generar nanopartículas más pequeñas y en un mayor número en comparación a la síntesis a altas temperaturas (Gallardo et al.). Por lo tanto, el uso de bacterias aisladas de ambientes antárticos beneficia en variados ámbitos la biosíntesis bacteriana de nanopartículas, ya que estas bacterias generalmente son de naturaleza psicrotolerantes y psicrófilas. Este artículo intenta entregar una breve revisión de las bacterias antárticas psicrófilas y psicrotolerantes sintetizadoras de nanopartículas, los posibles mecanismos que se asocian a esta síntesis y perspectivas futuras en relación a la biosíntesis bacteriana de nanopartículas.

Biosíntesis de nanopartículas bacterianas: Como ya se comentó anteriormente, las nanopartículas pueden ser aplicadas en diversas áreas, pero su síntesis química involucra un elevado costo monetario, por lo que desarrollar formas de síntesis que sean limpias, no tóxicas y ecoamigables es indispensable (Iravani, 2014). Es así como los investigadores, en búsqueda de nuevas alternativas de síntesis de nanopartículas han usado microorganismos y también extractos de plantas (Kirthi et al.). En este contexto, y tal como lo mencionan Mohanpuria et al. (2008), la naturaleza presenta una gran fuente de diversas maquinarias para la síntesis de nano y micro materiales inorgánicos, que ha abierto un amplio campo de estudio como lo es la biosíntesis de nanomateriales.

Según la literatura, varios géneros bacterianos pueden sintetizar nanopartículas inorgánicas a través de rutas intra y extracelulares ( Li et al., 2013), siendo los microrganismos reductores de metales pesados los mejores candidatos para ser utilizados en la síntesis de nanopartículas (Korbekandi et al., 2009; Iravani, 2014). Las bacterias son consideradas como potenciales biorreactores para la síntesis de nanopartículas de oro, plata, platino, paladio, titanio, dióxido de titanio, magnetita y sulfato de cadmio, entre otros (Iravani, 2014).

El uso de las bacterias en la síntesis de nanopartículas también, se ha posicionado como un proceso amigable con el medioambiente, debido a que requiere baja utilización de energía, posee compatibilidad medioambiental al usar microorganismos comunes del ambiente, reduce además los costos de mano de obra, es escalable, y se obtienen nanopartículas con igual o mayor estabilidad que las originadas a partir de la síntesis química (Correa-Llantén et al., 2013).

Uno de los primeros reportes en los cuales se hace alusión a la síntesis de nanopartículas en bacterias, que si bien aún no se denominaban como tal, es el trabajo de Lovley et al. (1987), en el cual se describe la síntesis de nanopartículas de magnetita por parte de una cepa de 
Shewanella putrefaciens. Este microorganismo reductor de hierro fue capaz de producir grandes cantidades de magnetita granulada ultra fina, observándose que las nanopartículas biosintetizadas estaban en un rango de medida de entre 10 a $50 \mathrm{~nm}$. Estas nanopartículas se generaron utilizando materia orgánica y la maquinaria de reducción de hierro de Shewanella putrefaciens. De igual forma Ahmad et al. (2003) lograron la biosíntesis de nanopartículas de oro monodispersas utilizando una bacteria alcalo tolerante identificada como Rhodococcus sp. Dicha biosíntesis se logró bajo condiciones biológicas extremas, tales como una alta alcalinidad y elevadas temperaturas. Por otra parte, Nair \& Pradeep (2002), demostraron que una cepa de Lactobacillus generó nanocristales de oro. Otro ejemplo de biosíntesis bacteriana de nanopartículas es el publicado por Klaus et al. (1999), quienes demostraron que la bacteria Pseudomonas stutzeri AG259, aislada desde una mina de plata, al ser colocada en una solución acuosa de nitrato de plata concentrado, expresó una gran capacidad de reducción de iones de plata $(\mathrm{Ag}+)$, llegando a la formación de nanopartículas de plata de tamaños homogéneos entre sí, y que se acumularon en el espacio periplásmico de la bacteria. De igual forma existen bacterias que han sintetizado nanopartículas de sulfato, como los nanocristales de sulfato de cadmio (CdS). Cunningham \& Lundie, (1993) describen que Clostridium thermoaceticum pudo precipitar $\mathrm{CdS}$ tanto en la superficie celular como en el medio de cultivo, y se describe que la síntesis la pudo llevar a cabo a partir de cloruro de cadmio $(\mathrm{CdCl} 2)$ en presencia de clorhidrato de cisteína, siendo la cisteína, posiblemente, la fuente de sulfato.

Si bien existe una amplia evidencia de bacterias capaces de sintetizar nanopartículas, en la actualidad, la diversidad de cepas bacterianas que son capaces de producir nanopartículas es limitado y con poca participación de microorganismos termófilos, psicrófilos y psicrotolerantes (Shivaji et al., 2011) debido a que la mayor parte de los reportes están acotados a microorganismos mesófilos. Es así como los organismos psicrófilos y psicrotolerantes requieren especial atención ya que al crecer a menores temperaturas pueden ofrecer nanopartículas que posean ventajas sobre las generadas por organismos termófilos y mesófilos, debido a que muchas de las nanopartículas pierden estabilidad al disminuir la temperatura cuando se lleva a cabo alguna aplicación de ellas (Kumar \& Mamidyala, 2011; Shivaji et al.).

Bacterias antárticas psicrófilas y psicrotolerantes productoras de nanopartículas: Entre los trabajos realizados en torno a la utilización de bacterias antárticas como productoras de nanopartículas, Pugin et al. (2014) reportaron una bacteria antártica psicrófila, identificada como Pseudomonas sp. cepa BNF22 que demostró tener la capacidad de sintetizar nanopartículas de telurio, de manera intracelular. Este grupo de investigación, además, pudo aislar una reductasa NADPH-dependiente de telurito a la cual se le asoció la capacidad de sintetizar estas nanopartículas en la bacteria. La clonación del gen que codifica para esta enzima, permitió su sobre expresión en una cepa de E. coli, la que fue capaz de generar las nanopartículas presentes en Pseudomonas sp. cepa BNF22. En su trabajo lograron la creación de un microorganismo con las condiciones óptimas para la síntesis de nanopartículas, lo que permitiría que el proceso sea más eficiente. En lo que respecta a la caracterización de las nanopartículas producidas, estas presentaron un tamaño de alrededor de $68 \mathrm{~nm}$, con actividad antibacteriana y baja citotoxicidad sobre líneas celulares eucariotas. En otro estudio Plaza et al. (2016), pudieron aislar tres bacterias antárticas capaces de producir nanopartículas de tipo quantum dots, específicamente CdS. La síntesis se realizó mediante la estimulación en el medio de crecimiento con $\mathrm{CdCl} 2$. Estas bacterias fueron identificadas como Pseudomonas fragi NBRC 12049, Pseudomonas psychrophila SAs-12 y Psychrobacter cibarius N-140, resistentes a altas concentraciones de telurito y cadmio, y fueron capaces de sintetizar CdS y CdTe al ser expuestas a iones de estos metales pesados. La síntesis de nanopartículas se observó a diferentes temperaturas y concentraciones de estos metales pesados, además según los análisis microscópicos, las bacterias almacenaban las nanopartículas sintetizadas en vesículas localizadas en el espacio periplásmico. De acuerdo a las características en las que se realizó la síntesis de nanopartículas, se trataría de cepas que podrían potenciar la biosíntesis de quantum dots, debido a los bajos requerimientos energéticos de la síntesis (Tabla I).

Por otra parte, Gallardo et al., reportaron otras cinco cepas de Pseudomonas sp de origen antártico, psicrotolerantes, las cuales fueron capaces de sintetizar quantum dots de tipo CdS. La identificación molecular demostró que cuatro correspondían a la especie Pseudomonas fragi, y una a Pseudomonas limi. Dentro de los hallazgos relevantes de este trabajo se puede mencionar que la principal característica que se les asocia a estas bacterias es la capacidad de realizar la síntesis de estas $\mathrm{CdD}$ a temperatura de $15^{\circ} \mathrm{C}$. Al igual que en los trabajos anteriormente descritos, estas bacterias se seleccionaron en base a su capacidad de resistencia al estrés oxidativo y resistencia a metales pesados, lo cual las hacia mejores candidatas para poder realizar síntesis de nanopartículas. La síntesis se llevó a cabo suplementando el medio de cultivo con $\mathrm{CdCl}_{2}\left(10 \mu \mathrm{g} \mathrm{ml}^{-1}\right)$. La caracterización de las nanopartículas indica que estas presentaron medidas entre 10 a $40 \mathrm{~nm}$. También, determinar que la síntesis fue generada a nivel extracelular, con acumulación de nanopartículas en el espacio perimembranal. Cabe señalar también que tres de las cuatro Pseudomonas fragi producían un tamaño de nanopartículas cercano a $100 \mathrm{~nm}$. 
Javani et al. (2015), describieron cuatro bacterias antárticas psicrófilas, identificadas como Psychrobacter sp., Aeromonas salmonicida, Pseudomonas veronii y Yersinia kristensenii, las cuales son capaces de producir nanopartículas de plata de forma extracelular. Es importante señalar que los microorganismos poseen la capacidad de producir las nanopartículas a $4{ }^{\circ} \mathrm{C}$ y $30{ }^{\circ} \mathrm{C}$, observándose diferencias en el tamaño de las nanopartículas, ya que a menor temperatura éstas son de menor tamaño, sin embargo, son más abundantes. La descripción de las nanopartículas indica que, dependiendo de la bacteria y de la temperatura utilizada, estas se caracterizaron por presentar formas esféricas y tamaños entre 5,0 y $11,1 \mathrm{~nm}$. Un dato relevante es que las nanopartículas permanecen estables durante varios meses. También, se determinó que estas nanopartículas poseían actividad inhibitoria contra bacterias del tipo Gram positivas, lo cual indica un posible campo de aplicación.

Mageswari et al. (2015), informan sobre tres bacterias psicrotolerantes, las cuales fueron identificadas como Pseudomonas mandelli, Pseudomonas jessenii y Pseudomonas gessardii, que tienen la capacidad de producir nanopartículas de plata. Todas las bacterias produjeron las nanopartículas en rangos de temperaturas de entre 5 a 30 ${ }^{\circ} \mathrm{C}$, demostrando tener una alta estabilidad, la cual estaría asociada a su baja temperatura de síntesis. En relación a la caracterización de las nanopartículas, la morfología que presentaron fue esférica y los diámetros variaron entre 1,9 y 14,1 nm. Por otra parte, la cepa Pseudomonas mandelli sintetizó las nanopartículas más pequeñas $(1,9$ a10 nm) y, además, esta cepa bacteriana realizó la síntesis de nanopartículas a temperaturas menores a $12{ }^{\circ} \mathrm{C}$, presentando alta estabilidad. También, demostraron la actividad larvicida de las nanopartículas de plata en contra de Anopheles subpictus y Culex tritaeniorhynchus. Finalmente, Shivaji et al. caracte- rizaron cinco bacterias psicrófilas, identificadas como Pseudomonas antarctica, Pseudomonas proteolítica, Pseudomonas meridiana, Arthrobacter kerguelensis y Arthrobacter gangotriensis, capaces de sintetizar nanopartículas de plata esféricas, cuyos tamaños estuvieron en un rango entre 6 y $13 \mathrm{~nm}$ y la síntesis fue generada en forma extracelular, presentando estabilidad durante varios meses. Este reporte corresponde al primer trabajo en el cual se generaron nanopartículas de plata a partir de bacterias psicrófilas del género Arthrobacter.

Mecanismos de síntesis: Los mecanismos a través de los cuales se sintetizan las nanopartículas bacterianas aún no están completamente descritos y se conoce poco sobre ellos, aun así, los más estudiados son los mecanismos de formación de nanopartículas metálicas. La síntesis de nanopartículas se asocia directamente con la capacidad de las bacterias para crecer en medios con altas concentraciones de metales pesados (Iravani, 2014; Plaza et al.). Esta resistencia incluye una serie de mecanismos tales como bombas trans-membranales, sistemas de expulsión o extrusión de metales, impermeabilidad a metales, alteración en la solubilidad y toxicidad mediante cambios en el estado redox de los iones metálicos, precipitación extracelular de metales, entre otros, lo cual le permite a estas bacterias desarrollar mecanismos enzimáticos y no enzimáticos que conducen a la síntesis de nanopartículas (Rouch et al., 1995 \& Beveridge et al., 1997).

Una de las vías de síntesis de nanopartículas bacterianas es la reportada por Lengke \& Southam (2005), quienes señalan que los metales en solución, que se encuentran en el medio de crecimiento de algunas bacterias, pueden unirse a tiosulfato y este complejo metal-tiosulfato ingresa a la célula. Una vez estando en el citoplasma

Tabla I. Nanopartículas sintetizadas por bacterias antárticas psicrófilas y psicrotolerantes

\begin{tabular}{|c|c|c|c|c|c|c|}
\hline Microorganismo & $\begin{array}{c}\text { Tipo de } \\
\text { nanopartícula }\end{array}$ & $\begin{array}{c}\text { Temperatura } \\
\text { de cultivo }\left({ }^{\circ} \mathrm{C}\right)\end{array}$ & $\begin{array}{c}\text { Tamaño } \\
(\mathbf{n m})\end{array}$ & Morfología & Ubicación & Referencias \\
\hline Pseudomonas antarctica & $\mathrm{Ag}$ & $8-30$ & $11,3 \pm 6,5$ & Esférica & Extracelular & Shi vaji et al., 2011 \\
\hline Pseudomonas proteolytica & $\mathrm{Ag}$ & $8-30$ & $7,2 \pm 2,4$ & Esférica & Extracelular & Shivaji et al., 2011 \\
\hline Pseudomonas meridiana & $\mathrm{Ag}$ & $8-30$ & $5,8 \pm 1,9$ & Esférica & Extracelular & Shivaji et al., 2011 \\
\hline Arthrobacter kerguelensis & $\mathrm{Ag}$ & $8-30$ & $8,5 \pm 2,7$ & Esférica & Extracelular & Shivaji et al., 2011 \\
\hline Arthrobacter gangotriensis & $\mathrm{Ag}$ & $8-30$ & $5,9 \pm 2,2$ & Esférica & Extracelular & Shivaji et al., 2011 \\
\hline Pseudomonas sp. BNF22 & $\mathrm{Te}$ & 30 & 68 & Triangular & Intracelular & Pugin et al., 2014 \\
\hline Pseudomonas fragi NBRC 12049 & $\mathrm{CdTe}$ & 28 & - & - & Intracelular & Plaza et al., 2014 \\
\hline Pseudomon as psychrophila SAs-12 & $\mathrm{CdTe}$ & 28 & - & - & Intracelular & Plaza et al., 2014 \\
\hline Psychrobacter cibarius N-140 & $\mathrm{CdTe}$ & 28 & - & - & Intracelular & Plaza et al., 2014 \\
\hline Pseudomon as fragii & $\mathrm{Cd}$ & 15 & $10-40$ & Esférica & Intracelular & Gallardo et al., 2014 \\
\hline Pseudomon as limii & $\mathrm{Cd}$ & 15 & $10-40$ & Esférica & Intracelular & Gallardo et al., 2014 \\
\hline Pseudomonas mandelli & Ag & 12 & $5,9 \pm 3,2$ & Esférica & Extracelular & Mageswari et al., 2014 \\
\hline Pseudomonas jessenii & $\mathrm{Ag}$ & $5-30$ & $11,0 \pm 2,7$ & Esférica & Extracelular & Mageswari et al., 2014 \\
\hline Pseudomon as gessardii, & $\mathrm{Ag}$ & $5-30$ & $7,4 \pm 3,7$ & Esférica & Extracelular & Mageswari et al., 2014 \\
\hline Psychrobacter sp & $\mathrm{Ag}$ & $4-30$ & $22,2-35,3$ & Esférica & Extracelular & Javani et al., 2015 \\
\hline Aeromonas salmonicida & Ag & $4-30$ & $26,5-33,8$ & Esférica & Extracelular & Javani et al., 2015 \\
\hline Yersinia kristensenii & $\mathrm{Ag}$ & $4-30$ & $25,5-27,4$ & Esférica & Extracelular & Javani et al., 2015 \\
\hline
\end{tabular}


bacteriano, este complejo metal-tiosulfato se disocia, permitiendo que el metal quede disponible para poder ser reducido en el citoplasma mediante enzimas intracelulares y así dar paso a la formación de nanopartículas, las que a su vez, pueden ser transportadas hacia la superficie celular o al espacio periplasmático de las bacterias (Fig. $1 \mathrm{~A}$ ). Otro mecanismo propuesto por Lengke \& Southam (2006) explica que al entrar el complejo metal-tiosulfato a la célula, este es metabolizado y se obtiene como producto final de su metabolismo HS- (sulfato de hidrógeno), el cual es liberado a través de poros de la membrana externa, provocando que disminuyan las condiciones redox alrededor de la célula, ocasionando la precipitación de los iones metálicos presentes en el medio; generando la síntesis extracelular de nanopartículas (Fig. 1 B).

Salunke et al., por otra parte, indican que los microorganismos, en general, pueden realizar la síntesis de nanopartículas porque pueden excretar al medio algunas enzimas extracelulares y una serie de metabolitos secundarios que ayudan en los procesos de reducción y formación de nanopartículas (Fig. 1 C)

Mukherjee et al. (2001) y Sharma et al. (2007), proponen que otro mecanismo de síntesis de nanopartículas es mediante la generación de una carga negativa en la pared bacteriana, lo que permite que los iones metálicos interaccionen con la pared o la superficie bacteriana debido a su carga. Esto permitiría que, enzimas presentes en el espacio periplasmático y en la membrana bacteriana, como por ejemplo hidrogenasas periplasmáticas interactúen con los iones metálicos y den origen a nanopartículas que se acumularán en el espacio extracelular o en el espacio periplasmático bacteriano (Iravani, 2014) (Fig.1 D).

También, existe un mecanismo de síntesis bacteriana de nanopartículas que es mediado por nitrato reductasas dependientes de NADH. Golinska et al. (2014), describen el mecanismo como un proceso que parte en el citoplasma bacteriano, en donde existe una oxidación del NADH, el electrón liberado es utilizado por la nitrato reductasa, enzima que posteriormente pasa al medio extracelular, en donde interacciona con nitratos unidos a metales, traspasando el electrón al metal que está unido al nitrato, generando que el ion metálico con carga + pase a ser una partícula con carga 0, dando origen a la formación de nanopartículas (Fig. 1 E).

Por otra parte, Nair \& Pradeep y Abdeen et al. (2014), proponen que en la síntesis bacteriana de nanopartículas también puede incidir la presencia de algunos grupos funcionales en las paredes y membranas bacterianas. Estos componentes bacterianos entregarían ciertas cargas locales, lo que facilitaría la formación de nanopartículas. De igual forma pigmentos bacterianos que se encuentren en las membranas y paredes pueden incidir en la formación de nanopartículas (Fig. 1 F).

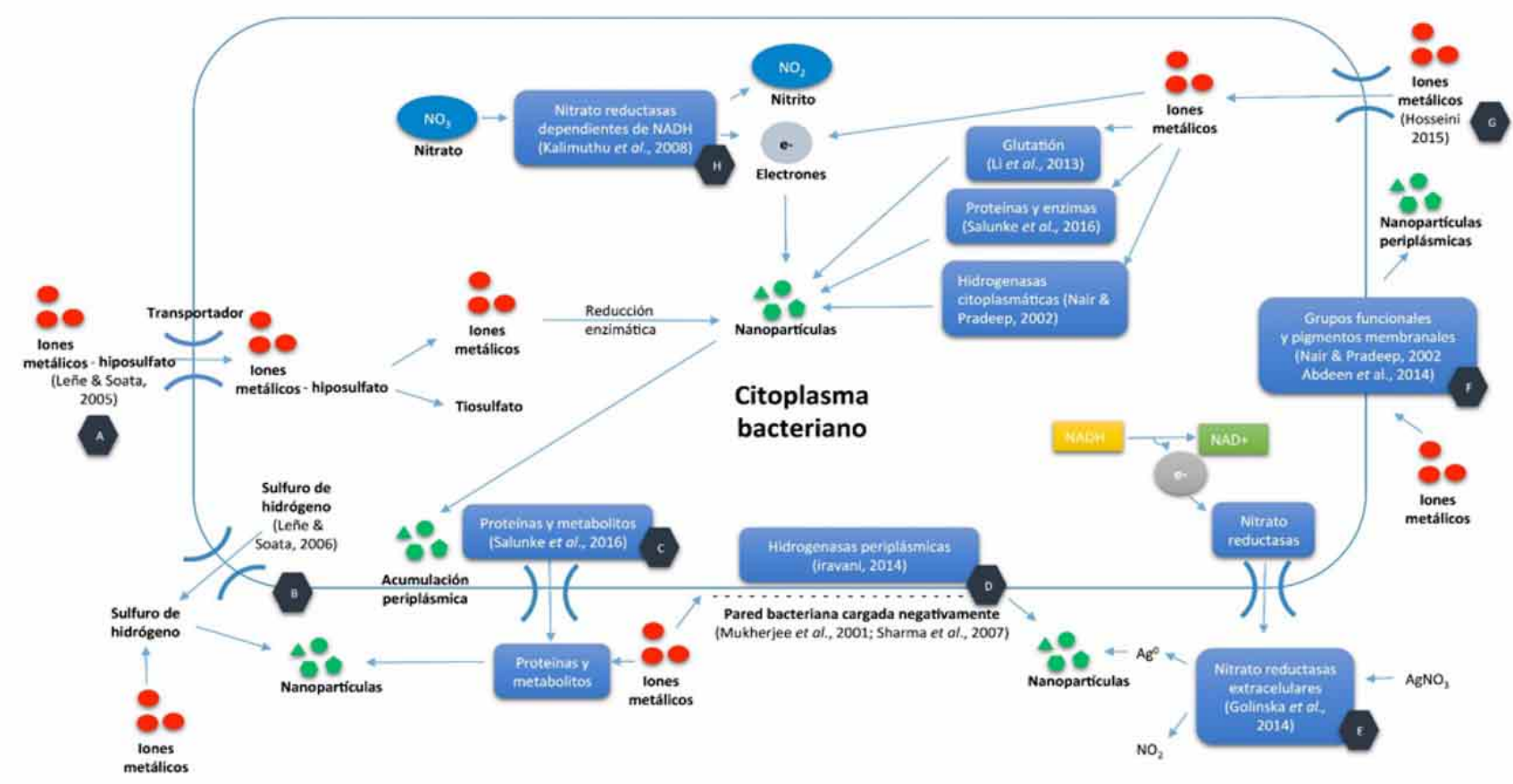

Fig. 1.Posibles mecanismos descritos para la biosíntesis bacteriana de nanopartículas A, D, G, H (Mecanismos de síntesis intracelulares), B, C, E, F (Mecanismos de Síntesis extracelulares) 
Hosseini \& Sarvi (2015), indica que en algunas bacterias, los iones metálicos presentes en el medio podrían entrar al citoplasma bacteriano. Una vez dentro del citoplasma bacteriano estos iones metálicos pueden ser reducidos mediante metabolitos como el glutatión (Li et al.), por la presencia de hidrogenasas citoplasmáticas (Nair \& Pradeep) u otro tipo de proteínas y enzimas que lleven a la bacteria a formar nanopartículas de forma intracelular. Dentro de estos mecanismos uno de los más conocidos es el que llevan a cabo las nitrato reductasas citoplasmáticas, las cuales pueden reducir estos iones metálicos y transformarlos en nanopartículas intracelulares. (Kalimuthu et al., 2008; Prabhu \& Poulose, 2012) (Fig. $1 \mathrm{G} \mathrm{y} \mathrm{H).}$

En este contexto, la Antártica se ha posicionado en el último tiempo como una fuente de microrganismos con capacidades antioxidantes excepcionales (Plaza et al.) ya que las condiciones extremas de este continente, tales como la radiación ultravioleta, baja disponibilidad de nutrientes, alta salinidad, entre otras características de los suelos, han hecho que los microorganismos que ahí habitan desarrollen mecanismos de resistencia a estrés oxidativo (Chattopadhyay et al. \& Kulkarni et al., 2014). Algunas adaptaciones enzimáticas y no enzimáticas descritas en bacterias antárticas son glutatión s-transferasa (Shi et al., 2014), glutatión reductasa (Pugin et al., 2014), tioredoxina (Falasca et al., 2012) catalasas (Tribelli et al., 2012), super óxido dismutasas (Zheng et al., 2006), carotenoides (Dieser et al., 2010) y óxido reductasas (Madonna et al., 2006).

\section{CONCLUSION}

En el último tiempo se ha incrementado el número de investigaciones que se realizan con la biogénesis de nanopartículas, pero queda aún mucho por hacer en lo que se refiere a la optimización de estos protocolos, principalmente en mejoras para poder controlar el tamaño, la forma y la cantidad de nanopartículas sintetizadas. El uso de bacterias antárticas psicrotolerantes y/o psicrófilas entrega una venta- ja por una parte, debido a la abundancia en ese entorno de bacterias resistentes a metales pesados y por otra parte, debido a las condiciones de temperatura a las cuales crecen estos microorganismos, lo cual es una ventaja en la producción y también se traduce en una versatilidad de las nanopartículas generadas. Sin embargo, se requiere optimizar las condiciones de estabilidad de las nanopartículas

Otro aspecto que requiere especial atención es el proceso de extracción y purificación de las nanopartículas ya que hay pocos trabajos que se enfocan en este paso indispensable para su biosíntesis, por lo tanto el desarrollo de una metodología eficiente y también escalable industrialmente puede hacer mucho más atractiva la biosíntesis de nanopartículas. Todo lo anterior complementará el escalamiento industrial y por ende el uso masivo de estos organismos sintetizadores de nanopartículas, ya que para ello se debe tener en cuenta procesos como cultivos bacterianos, recolección del cultivo, síntesis de nanopartículas mediante adición de iones, separación de células por filtración, extracción y estabilización de nanopartículas, formulación de productos y control de calidad, por ello la importancia de refinar la investigación en todos los campos señalados anteriormente.

En el contexto general de nanopartículas, al analizar la información disponible relacionada con las vías de síntesis, queda claro que estos mecanismos que ayudan a las bacterias a generar nanopartículas de forma intra o extracelular aún no están totalmente descritos, sin embargo existe una relación clara entre la resistencia a metales pesados y la capacidad de sintetizar nanopartículas, debido a la maquinaria metabólica que se expresa en las bacterias en estas condiciones de estrés, es así como por ejemplo las reductasas están presentes en varios de los mecanismos propuestos en la actualidad. Finalmente, la biosíntesis de nanopartículas mediante el uso de bacterias es un área de la nanotecnología que posee grandes proyecciones, sin embargo procesos como el control del tamaño de las nanopartículas, su forma y estabilidad, aún están en etapas de desarrollo y por ende se requieren más estudios en esta prometedora área de investigación llamada nanotecnología.

SANTOS, A.; TRONCOSO, C.; LAMILLA, C.; LLANQUINAO, V.; PAVEZ, M. \& BARRIENTOS, L. Nanoparticles synthesized by Antarctic bacteria and their possible mechanisms of synthesis. Int J.Morphol., 35(1):26-33, 2017.

SUMMARY: In recent years microorganisms as fungi, yeasts and especially bacteria have been used to produce nanoparticles biosynthesis. Several types of bacteria are described as nanoparticles producers, however, psychrophilic and psychrotolerant bacterias have not been studied widely, although its use in the production of nanoparticles could provide advantages related to the stability of nanoparticles, energy expenditure on its production, while being an environmentally friendly alternative. This article provides a brief overview of Antarctic bacterias, both psychrophilic and psychrotolerant that synthesis nanoparticles, possible mechanisms associated to this synthesis and future perspectives related to bacterial biosynthesis of nanoparticles. 


\section{REFERENCIAS BIBLIOGRÁFICAS}

Abdeen, S.; Geo, S.; Sukanya, S.; Praseetha, P. K. \& Dhanya, R. P. Biosynthesis of silver nanoparticles from Actinomycetes for therapeutic applications. Int. J. Nano Dimens., 5(2):155-62, 2014.

Ahmad, A.; Senapati, S.; Khan, M. I.; Kumar, R.; Ramani, R.; Srinivas, V. \& Sastry, M. Intracellular synthesis of gold nanoparticles by a novel alkalotolerant actinomycete, Rhodococcus species. Nanotechnology, 14(7):824-8, 2003.

Bansal, P.; Duhan, J. S. \& Gahlawat, S. K. Biogenesis of nanoparticles: A review. Afr. J. Biotechnol., 13(28):2778-85, 2014

Beveridge, T. J.; Hughes, M. N.; Lee, H.; Leung, K. T.; Poole, R. K.; Savvaidis, I.; Silver, S. \& Trevors, J. T. Metal-microbe interactions: contemporary approaches. Adv. Microb. Physiol., 38:177-243, 1997.

Chattopadhyay, M. K.; Raghu, G.; Sharma, Y. V.; Biju, A. R.; Rajasekharan, M. V. \& Shivaji, S. Increase in oxidative stress at low temperature in an antarctic bacterium. Curr. Microbiol., 62(2):544-6, 2011.

Correa-Llantén, D. N.; Muñoz-Ibacache, S. A.; Castro, M. E.; Muñoz, P. A. \& Blamey, J. M. Gold nanoparticles synthesized by Geobacillus sp. strain ID17 a thermophilic bacterium isolated from Deception Island, Antarctica. Microb. Cell Fact., 12:75, 2013.

Cunningham, D. P. \& Lundie, L. L. Jr. Precipitation of cadmium by Clostridium thermoaceticum. Appl. Environ. Microbiol., 59(1):7-14, 1993.

Daniel, M. C. \& Astruc, D. Gold nanoparticles: assembly, supramolecular chemistry, quantum-size-related properties, and applications toward biology, catalysis, and nanotechnology. Chem. Rev., 104(1):293-346, 2004.

Dieser, M.; Greenwood, M. \& Foreman, C. M. Carotenoid pigmentation in Antarctic heterotrophic bacteria as a strategy to withstand environmental stresses. Arct. Antarct. Alp. Res., 42(4):396-405, 2010.

Dowling, A. R.; Clift, R.; Grobert, N.; Hutton, D. D.; Oliver, R.; O'Neill, B. O.; Pethica, J.; Pidgeon, N.; Porritt, J.; Ryan, J.; Seaton, A.; Tendler, S.; Welland, M. \& Whatmore, R. Nanoscience and Nanotechnologies: Opportunities and Uncertainties. London, The Royal Society, 2004. pp.7-13.

Fadeel, B. \& Garcia-Bennett, A. E. Better safe than sorry: Understanding the toxicological properties of inorganic nanoparticles manufactured for biomedical applications. Adv. Drug Deliv. Rev., 62(3):362-74, 2010.

Falasca, P.; Evangelista, G.; Cotugno, R.; Marco, S.; Masullo, M.; De Vendittis, E. \& Raimo, G. Properties of the endogenous components of the thioredoxin system in the psychrophilic eubacterium Pseudoalteromonas haloplanktis TAC 125. Extremophiles, 16(3):53952, 2012.

Gallardo, C.; Monrás, J. P.; Plaza, D. O.; Collao, B.; Saona, L. A.; DuránToro, V.; Venegas, F. A.; Soto, C.; Ulloa, G.; Vásquez, C. C.; Bravo, D. \& Perez-Donoso, J. M. Low-temperature biosynthesis of fluorescent semiconductor nanoparticles (CdS) by oxidative stress resistant Antarctic bacteria. J. Biotechnol., 187:108-15, 2014.

Golinska, P.; Wypij, M.; Ingle, A. P.; Gupta, I.; Dahm, H. \& Rai, M. Biogenic synthesis of metal nanoparticles from actinomycetes: biomedical applications and cytotoxicity. Appl. Microbiol. Biotechnol., 98(19):8083-97, 2014.

Hosseini, M. R., \& Sarvi, M. N. Recent achievements in the microbial synthesis of semiconductor metal sulfide nanoparticles. Mater. Sci. Semicond. Process., 40, 293-301, 2015.

Iravani, S. Bacteria in nanoparticle synthesis: current status and future prospects. Int. Sch. Res. Not., 2014:359316, 2014.

Iravani, S.; Korbekandi, H.; Mirmohammadi, S. V. \& Zolfaghari, B. Synthesis of silver nanoparticles: chemical, physical and biological methods. Res. Pharm. Sci., 9(6):385-406, 2014.

Javani, S.; Marín, I.; Amils, R.; \& Abad, J. P. Four psychrophilic bacteria from Antarctica extracellularly biosynthesize at low temperature highly stable silver nanoparticles with outstanding antimicrobial activity. Colloids Surf. A Physicochem. Eng. Asp., 483:60-9, 2015.

Kalimuthu, K.; Suresh Babu, R.; Venkataraman, D.; Bilal, M. \& Gurunathan, S. Biosynthesis of silver nanocrystals by Bacillus licheniformis. Colloids Surf. B Biointerfaces, 65(1):150-3, 2008.

Kirthi, A. V.; Jayaseelan, C. \& Rahuman, A. Biosynthesis and Characterization of Different Nanoparticles and its Larvicidal Activity against Human Disease Vectors. In: Kim S. K. (Ed.). Marine Biomaterials. Boca Raton, CRC Press, 2013. pp.273-88.

Klaus, T.; Joerger, R.; Olsson, E. \& Granqvist. C. G. Silver-based crystallin nanoparticles, microbially fabricated. Proc. Nat. Acad. Sci. U. S. A., 96(24):13611-4, 1999.

Klaus-Joerger, T.; Joerger, R.; Olsson, E. \& Granqvist, C. Bacteria as workers in the living factory: metal-accumulating bacteria and their potential for materials science. Trends Biotechnol., 19(1):15-20, 2001.

Korbekandi, H.; Iravani, S. \& Abbasi, S. Production of nanoparticles using organisms. Crit. Rev. Biotechnol., 29(4):279-306, 2009.

Kulkarni, H. M.; Swamy Ch. V. \& Jagannadham, M. V. Molecular characterization and functional analysis of outer membrane vesicles from the antarctic bacterium Pseudomonas syringae suggest a possible response to environmental conditions. J. Proteome Res., 13(3):134558,2014

Kumar, C. G. \& Mamidyala, S. K. Extracellular synthesis of silver nanoparticles using culture supernatant of Pseudomonas aeruginosa. Colloids Surf. B Biointerfaces, 84(2):462-6, 2011.

Lengke, M. F. \& Southam, G. The effect of thiosulfate-oxidizing bacteria on the stability of the gold-thiosulfate complex. Geochim. Cosmochim. Acta, 69(15):3759-72, 2005.

Lengke, M., \& Southam, G. Bioaccumulation of gold by sulfate-reducing bacteria cultured in the presence of gold(I)-thiosulfate complex. Geochim. Cosmochim. Acta, 70(14):3646-61, 2006.

Lengke, M. F.; Fleet, M. E. \& Southam, G. Biosynthesis of silver nanoparticles by filamentous cyanobacteria from a silver(I) nitrate complex. Langmuir, 23(5):2694-9, 2007.

Li, Y.; Cui, R.; Zhang, P.; Chen, B. B.; Tian, Z. Q.; Li, L.; Hu, B.; Pang, D. W. \& Xie, Z. X. Mechanism-oriented controllability of intracellular quantum dots formation: the role of glutathione metabolic pathway. A. C. S. Nano, 7(3):2240-8, 2013.

Lovley, D. R.; Stolz, J. F.; Nord Jr., G. L. \& Phillips, E. J. P.. Anaerobic production of magnetite by a dissimilatory iron-reducing microorganism. Nature, 330(6145):252-4, 1987.

Madonna, S.; Papa, R.; Birolo, L.; Autore, F.; Doti, N.; Marino, G.; Quemeneur, E.; Sannia, G.; Tutino, M. L. \& Duilio, A. The thioldisulfide oxidoreductase system in the cold-adapted bacterium Pseudoalteromonas haloplanktis TAC 125: discovery of a novel disulfide oxidoreductase enzyme. Extremophiles, 10(1):41-51, 2006.

Mageswari, A.; Subramanian, P.; Ravindran, V.; Yesodharan, S.; Bagavan, A.; Rahuman, A. A.; Karthikeyan, S. \& Gothandam, K. M. Synthesis and larvicidal activity of low-temperature stable silver nanoparticles from psychrotolerant Pseudomonas mandelii. Environ. Sci. Pollut. Res. Int., 22(7):5383-94, 2015.

Mohanpuria, P.; Rana, N. K. \& Yadav, S. K. Biosynthesis of nanoparticles: technological concepts and future applications. J. Nanoparticle Res., 10(3):507-17, 2008.

Monrás, J. P.; Díaz, V.; Bravo, D.; Montes, R. A.; Chasteen, T. G.; OsorioRomán, I. O.; Vásquez, C. C. \& Pérez-Donoso, J. M. Enhanced glutathione content allows the in vivo synthesis of fluorescent CdTe nanoparticles by Escherichia coli. PLoS One, 7(11):e48657, 2012.

Mukherjee, P.; Ahmad, A.; Mandal, D.; Senapati, S.; Sainkar, S. R.; Khan, M. I.; Ramani, R., Parischa, R.; Ajayakumar, P. V.; Alam, M.; Sastry, M. \& Kumar, R. Bioreduction of $\mathrm{AuCl}(4)(-)$ Ions by the Fungus, Verticillium sp. and Surface Trapping of the Gold Nanoparticles 
Formed D.M. and S.S. thank the Council of Scientific and Industrial Research (CSIR), Government of India, for financial assistance. Angew. Chem. Int. Ed. Engl., 40(19):3585-8, 2001.

Nair, B. \& Pradeep, T. Coalescence of nanoclusters and formation of submicron crystallites assisted by Lactobacillus strains. Cryst. Growth Des., 2(4):293-8, 2002.

Plaza, D. O.; Gallardo, C.; Straub, Y. D.; Bravo, D. \& Pérez-Donoso, J. M. Biological synthesis of fluorescent nanoparticles by cadmium and tellurite resistant Antarctic bacteria: exploring novel natural nanofactories. Microb. Cell Fact., 15:76, 2016.

Prabhu, S. \& Poulose, E. K. Silver nanoparticles: mechanism of antimicrobial action, synthesis, medical applications, and toxicity effects. Int. Nano Lett., 2:32, 2012.

Pugin, B.; Cornejo, F. A.; Muñoz-Díaz, P.; Muñoz-Villagrán, C. M.; VargasPérez, J. I.; Arenas, F. A. \& Vásquez, C. C. Glutathione reductasemediated synthesis of tellurium-containing nanostructures exhibiting antibacterial properties. Appl. Environ. Microbiol., 80(22):7061-70, 2014.

Pérez-Donoso, J. M.; Monrás, J. P.; Bravo, D.; Aguirre, A.; Quest, A. F.; Osorio-Román, I. O.; Aroca, R. F.; Chasteen, T. G. \& Vásquez, C. C. Biomimetic, mild chemical synthesis of CdTe-GSH Quantum dots with improved biocompatibility. PLoS One, 7(1):e30741, 2012.

Rouch, D. A.; Lee, B. T. \& Morby, A. P. Understanding cellular responses to toxic agents: a model for mechanism-choice in bacterial metal resistance. J. Ind. Microbiol., 14(2):132-41, 1995.

Salunke, B. K.; Sawant, S. S.; Lee, S. I. \& Kim, B. S. Microorganisms as efficient biosystem for the synthesis of metal nanoparticles: current scenario and future possibilities. World J. Microbiol. Biotechnol., 32(5):88, 2016.

Sharma, N. C.; Sahi, S. V.; Nath, S.; Parsons, J. G.; Gardea-Torresdey, J. L. $\& \mathrm{Pal}, \mathrm{T}$. Synthesis of plant-mediated gold nanoparticles and catalytic role of biomatrix-embedded nanomaterials. Environ. Sci. Technol., 41(14):5137-42, 2007.

Shi, Y.; Wang, Q.; Hou, Y.; Hong, Y.; Han, X.; Yi, J.; Qu, J. \& Lu, Y. Molecular cloning, expression and enzymatic characterization of glutathione S-transferase from Antarctic sea-ice bacteria Pseudoalteromonas sp. ANT506. Microbiol. Res., 169(2-3):179-84, 2014.

Shivaji, S.; Madhu, S. \& Singh, S. Extracellular synthesis of antibacterial silver nanoparticles using psychrophilic bacteria. Process Biochem., 46(9):1800-7, 2011.

Tribelli, P. M.; Raiger Iustman, L. J.; Catone, M. V.; Di Martino, C.; Revale, S.; Méndez, B. S. \& López, N. I. Genome sequence of the polyhydroxybutyrate producer Pseudomonas extremaustralis, a highly stress-resistant Antarctic bacterium. J. Bacteriol., 194(9):2381-2, 2012.

Yakub, I. \& Soboyejo, W. O. Adhesion of E. coli to silver- or copper-coated porous clay ceramic surfaces. J. Appl. Phys., 111:124324, 2012.

Zheng, Z.; Jiang, Y. H.; Miao, J. L.; Wang, Q. F.; Zhang, B. T. \& Li, G. Y. Purification and characterization of a cold-active iron superoxide dismutase from a Psychrophilic Bacterium, Marinomonas sp. NJ522. Biotechnol. Lett., 28(2):85-8, 2006.

\author{
Dirección para correspondencia: \\ Leticia Barrientos \\ Doctor en Ciencias \\ Laboratorio Biología Molecular Aplicada \\ Universidad de La Frontera \\ Temuco \\ CHILE
}

Email: leticia.barrientos@ufrontera.cl

Recibido : 07-10-2016

Aceptado: 23-11-2016 